\title{
Neglected Ocular Trauma by Patient and Local Practitioner
}

Bhandari $\mathrm{N}^{1}$, Thapa $\mathrm{BB}^{2}$

\section{ABSTRACT}

Ocular trauma is the major cause of vision loss. The circumstances and agents implicated in such injuries are diverse. In context of Nepal, fall injury is most common form of accident. We present a case of penetrating ocular trauma in 30 years old house wife who fell from tree. The impacted wooden foreign body was removed on emergency basis. Delay in seeking specialty medical help by patients and ignorance of local practitioner for referral resulted in macerated conjunctiva. This case highlights the propensity of grievous ocular trauma in domestic environment.

\section{Keywords: Barrier to seek care, Blindness, Ocular trauma,}

1. Dr. Nirajan Bhandari

2. Dr. Bikram Bahadur Thapa

\section{Address for Correspondence:}

Dr. Nirajan Bhandari

MBBS

House Officer

Nepalgunj Medical College \& Teaching Hospital

Nepalgunj, Banke

drnirajan017@gmail.com

Mobile number: 9843113677

\section{INTRODUCTION}

Ocular trauma is most common cause of unilateral blindness. Its prevalence is common in pediatric age group. However it varies along with lifestyle, socio-economic status, creative activities, and traffic state. The injuries are most frequently occurred in actively working people and, men are five times more affected than women. About half a million people in the world are blind as a result of Eye injuries. About $30-40 \%$ of monocular blindness is due to ocular trauma. Woods, sharp object and glass are the most common agents of penetrating ocular trauma.

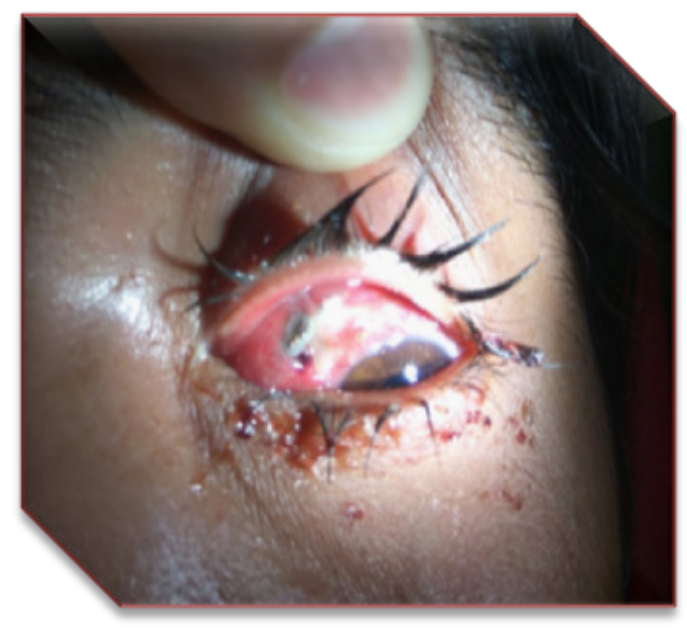

Figure 1: Penetrating ocular trauma

According to report publish by US National Institute of Health, about $38-52 \%$ of all cases presenting to ophthalmic emergency are Ocular trauma. National population based survey of

blindness in Nepal (1981) found a blindness prevalence rate of $0.84 \%$ with trauma responsible for $7.9 \%$ of monocular blindness.

\section{CASE REPORT}

30 years old housewife resident of Dailekh presented in Outpatient department of Nepalgunj medical college, Nepalgunj with history of fall injury from tree of height two meter 7 days back. She complained of bleeding,discomfort on her left eye with profuse watering and redness. Her vision was blurred from the day of incident.

On further inquiry, she reported that she delayed in seeking medical help for 4 days. She was referred to NGMC Nepalgunj on her 7th day of incident from Community Eye care centre, Dailekh via Nepal Red Cross Eye hospital, Surkhet.

On clinical examination her Left eye lids were swollen and congested, eye opening was not full, conjunctiva wascongested, swollen and has multiple defect supero-nasally on 9-12 o'clock with visible foreign body in sub-conjunctival space. The posterior margin of the foreign body couldn't be palpated. The cornea, anterior and posterior segment examination revealed no abnormality. Left eye visual acuity was 6/9 (P) whereas right eye being 6/6.

Ultrasound scan was done immediately which was concluded as Low medium reflecting mass on anterior orbitsuggestive of wooden foreign body in anterior orbit.

Conservative treatmentwas started with prophylactic oral antibiotics, Antibiotic and antifungal eye drops. Emergency surgery to remove foreign body was planned.Surgery was done on peri bulbar block through conjunctival approach. The 
superior conjunctiva was macerated due to multiple attempts by local practitioner, localized peritomy was made. Limbal traction suture was used to expose fornix and anterior orbit. Tenon's capsule and conjunctiva were separated from foreign body. Using toothed forceps 3 broken pieces of foreign body were extracted. The underlying sclerawas thinned out and lack episcleral tissue. Cornea was normal. After cleaning peritomy was closed using 8.0 poly glycolic acid (vicryl) absorbable suture and patch was applied. Post-operative regimen included oral antibiotic, topical antibiotic, antifungal and lubricants.

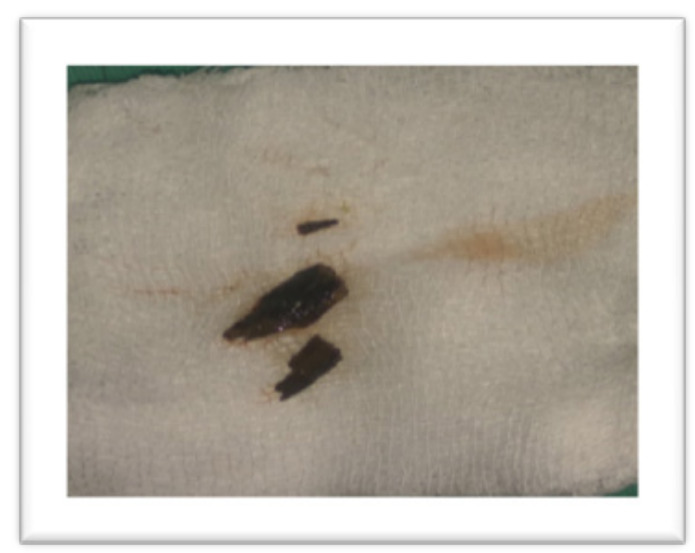

Figure 2: Extracted foreign body

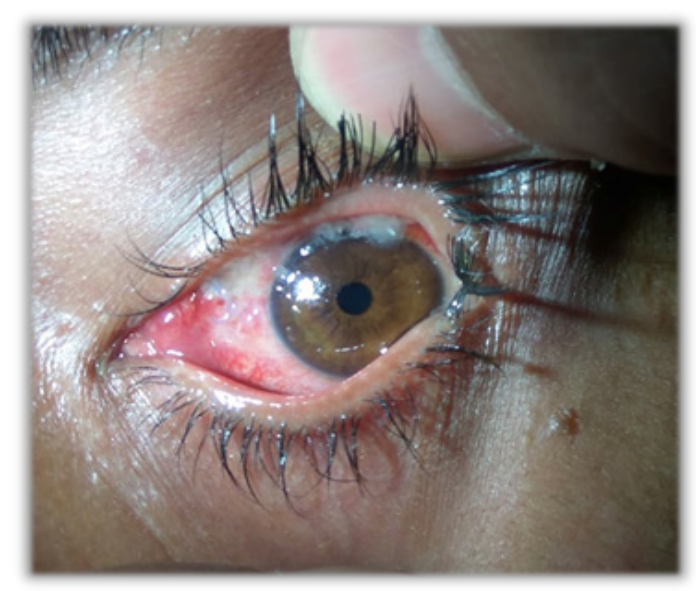

Figure3: Eye Post-Operative view

\section{DISCUSSION}

Penetrating ocular trauma is the important cause of Monocular blindness. Prompt diagnosis and treatment preferably within first twenty four hours, are essential for best possible prognosis. In context of Nepal, the detrimental effects of delayed case reporting or case outside of the specialty eye clinic may reflect geographic or economic barrier to care. For optimal vision outcome patients who are injured in a rural setting should recognize the injury and seek early case at specialty Eye care facility. VA is one of the important prognostic clues to final visual outcomes. On lowest scheme Local practitioner should be well trained for referral on the basis of VA outcome. Good discipline in manner of referral shows excellent outcome in patient'sprognosis. There is need to implement Eye health awareness programme targeted at increasing safety measures in working site. Workers working in field should be provided with personal protective equipment for safety measure.

\section{REFERENCES}

https://www.iapb.org/resources/epidemiology-of-blindnessin-nepal/

https://bjo.bmj.com/content/88/4/456

https://www.ncbi.nlm.nih.gov/pmc/articles/PMC4139697/

https://www.omicsonline.org/open-access/a-typicalpenetrating-ocular-trauma--case-report-2329-9126-1000234. php

http://www.doiserbia.nb.rs/img/doi/0042-8450/2010/004284501012983J.pdfhttps://www.ncbi.nlm.nih.gov/pmc/ articles/PMC313907/

https://www.ncbi.nlm.nih.gov/pmc/articles/PMC3003858/ 